\title{
RANCANGAN PENGEMBANGAN PELABUHAN PERIKANAN PELABUHANRATU TERKAIT DENGAN PENINGKATAN KARAKTERISTIK KELAS PELABUHAN PERIKANAN DAN PEMILIHAN JENIS KAPAL PENANGKAP IKAN
}

\author{
Iswadi Nur ${ }^{1}$, Bambang Sudjasta ${ }^{1}$ dan Budhi Martana ${ }^{2}$ \\ Program Studi S-1 Teknik Perkapalan ${ }^{1}$, Program Studi S-1 Teknik Mesin ${ }^{2}$ \\ Email : iswadi.tp@gmail.com
}

\begin{abstract}
Pelabuhanratu National Fishing Port can be changed to Pelabuhanratu Oceanic Fishing Port, but it should be proper to the class characteristic regulation of KKP, number 16, 2006. It has several condition, as ; the fishing vessel fleet have service area in the ZEE territorial and the International Ocean, the quay wall fasility > $60 \mathrm{GT}$, the port quay dimension has length $>300 \mathrm{~m}$ and deep of sea water $>3 \mathrm{~m}$, amount of fish production 60 ton per day, the fishing port capacity $>$ 6000 GT per day, it has the quality assurance facility of fish production, the area of fishing port $>$ 30 hectares, it has the zone of fish processing industry. The result of research had many factors that had not been proper to the KKP regulation, as; amount of fish production $=25,030$ ton per day, the fishing port capacity approximately 268,957 GT per day, the area of fishing port $<30$ hectares, the zone of fish processing industry had not completed, so Pelabuhanratu National Fishing Port can not be changed to Pelabuhanratu Oceanic Fishing Port. Related to the fishing vessel that to be proper to the characteristic of its service area, as ; the capacity of fishing vessel up to 60 GT and minimum speed 12,5 knots, the fishing vessel has minimum 6 fish holds, the location of fish hold in the middle body, the fishing vessel hull has the bilge keel plate, and the material of hull fishing vessel to be made of wooden, steel, aluminium, or fiberglass.
\end{abstract}

Keyword : National Fishing Port, Oceanic Fishing Port, fishing vessel.

\section{Bab I Pendahuluan}

\subsection{Latar Belakang}

Menurut Peraturan Menteri Kelautan dan Perikanan Nomor : 16 tahun 2006, Karakteristik Kelas Pelabuhan Perikanan terbagi dalam 4 kelas, yaitu Pelabuhan Perikanan Samudera (PPS), Pelabuhan Perikanan Nusantara (PPN), Pelabuhan Perikanan Pantai (PPP), Pangkalan Pendaratan Ikan (PPI). Dari keempat kelas tersebut PPS berjumlah 6 buah, PPN berjumlah 15 buah, PPP berjumlah sekitar 44 buah, dan selebihnya PPI berjumlah 937 buah.

Pelabuhan Perikanan Samudera ;

\begin{tabular}{|r|l|l|}
\hline No & Nama Pelabuhan & \multicolumn{1}{|c|}{ Provinsi } \\
\hline 1. & $\begin{array}{l}\text { Pelabuhan Perikanan } \\
\text { Samudera Nizam } \\
\text { Zahman Jakarta }\end{array}$ & $\begin{array}{l}\text { DKI Jakarta, Jl. } \\
\text { Muara Baru } \\
\text { Samudera Jakarta }\end{array}$ \\
\hline 2. & $\begin{array}{l}\text { Pelabuhan Perikanan } \\
\text { Samudera Kendari }\end{array}$ & $\begin{array}{l}\text { Sulawesi Tenggara, } \\
\text { Jl. Samudera No.1 } \\
\text { Kendari }\end{array}$ \\
\hline 3. & $\begin{array}{l}\text { Pelabuhan Perikanan } \\
\text { Samudera Belawan }\end{array}$ & $\begin{array}{l}\text { Sumatera Utara, Po } \\
\text { Box 20 Belawan }\end{array}$ \\
\hline 4. & $\begin{array}{l}\text { Pelabuhan Perikanan } \\
\text { Samudera Cilacap }\end{array}$ & $\begin{array}{l}\text { Jawa Tengah, Jl. } \\
\text { Teluk Penyu, } \\
\text { Cilacap }\end{array}$ \\
\hline 5. & $\begin{array}{l}\text { Pelabuhan Perikanan } \\
\text { Samudera Bitung }\end{array}$ & $\begin{array}{l}\text { Sulawesi Utara, } \\
\text { Kec. Bitung }\end{array}$ \\
\hline 6. & $\begin{array}{l}\text { Pelabuhan Perikanan } \\
\text { Samudera Bungus }\end{array}$ & Sumatera Barat \\
\hline
\end{tabular}

Sumber:www.kkp.go.id

Pelabuhan Perikanan Nusantara :

\begin{tabular}{|l|l|l|}
\hline No & \multicolumn{1}{|c|}{$\begin{array}{c}\text { Nama } \\
\text { Pelabuhan } \\
\text { Perikanan } \\
\text { Nusantara }\end{array}$} & \multicolumn{1}{|c|}{ Provinsi } \\
\hline 1. & Sibolga & $\begin{array}{l}\text { Sumatera Utara, Jl. Dolok } \\
\text { Martimbang no. 48 Sibolga }\end{array}$ \\
\hline 2. & $\begin{array}{l}\text { Pelabuhan } \\
\text { Ratu }\end{array}$ & $\begin{array}{l}\text { Jawa Barat, Jl. Pelita P. Ratu } \\
\text { Sukabumi }\end{array}$ \\
\hline 3. & Pekalongan & $\begin{array}{l}\text { Jawa Tengah, Jl. WR. Supratman, } \\
\text { Pekalongan }\end{array}$ \\
\hline 4. & Brondong & $\begin{array}{l}\text { Jawa Timur, Jl. Raya Brondong no. } \\
17 \text { Lamongan }\end{array}$ \\
\hline 5. & Karangantu & Banten, Po Box 23 Banten \\
\hline 6. & Karimumjawa & $\begin{array}{l}\text { Jawa Tengah, Kec. Karimumjawa, } \\
\text { Jepara }\end{array}$ \\
\hline 7. & Prigi & $\begin{array}{l}\text { Jawa Timut, Kec. Watulimo, } \\
\text { Trenggalek }\end{array}$ \\
\hline 8. & $\begin{array}{l}\text { Pantai } \\
\text { Lampulo }\end{array}$ & $\begin{array}{l}\text { Nangroe Aceh Darussalam, Po. Box } \\
\text { 23 Banda Aceh }\end{array}$ \\
\hline 9. & Pemangkat & $\begin{array}{l}\text { Kalimantan Barat, Jl. Penjajap Kab. } \\
\text { Sambas }\end{array}$ \\
\hline 10. & Teluk Batang & $\begin{array}{l}\text { Kalimantan Selatan, Jl. Sutan Syahrir } \\
\text { 16 Pontianak }\end{array}$ \\
\hline 11. & $\begin{array}{l}\text { Tanjung } \\
\text { Pandan }\end{array}$ & $\begin{array}{l}\text { Sumatera Selatan, Jl. Pantai II } \\
\text { Tanjung Pandan }\end{array}$ \\
\hline 12. & Ambon & $\begin{array}{l}\text { Maluku, Jl. Sultan Hasanuddin, } \\
\text { Ambon }\end{array}$ \\
\hline 13. & Ternate & $\begin{array}{l}\text { Maluku Utara, Jl. Pasar Inpres } \\
\text { Ternate } \\
\text { Tenggara Jl. Damar, Kab. Maluku } \\
\text { Bali, Kec. Negara, Kab. Jembrana }\end{array}$ \\
\hline 14. & Tual & Pengalengan \\
\hline Sumber:www.kkp.go.id \\
\hline 15
\end{tabular}


Pelabuhan Perikanan Samudera jumlahnya sangat sedikit tidak sebanding dengan luas wilayah lautan Indonesia. Jumlah Pelabuhan Perikanan Samudera semestinya ditingkatkan untuk meningkatkan jumlah produksi perikanan tangkap secara nasional. PPN Pelabuhanratu memiliki potensi untuk ditingkatkan kelasnya karena terletak di pesisir pantai berhadapan langsung dengan perairan Samudera Indonesia, dimana karakteristik perairan PPN Pelabuhanratu sama dengan PPS Cilacap.

Peningkatan kelas PPN Pelabuhanratu menjadi PPS tersebut dapat mengoptimalkan peran dan fungsi PPN Pelabuhanratu sebagai pusat transaksi perikanan dan media meningkatkan pendapatan masyarakat. Peningkatan kapasitas dari fasilitas sarana dan prasarana PPN Pelabuhanratu bertujuan untuk meningkatkan produksi dan produktivitas perikanan, serta mendorong berkembangnya usaha perikanan rakyat dan membantu tercapainya iklim yang kondusif bagi pertumbuhan dunia usaha perikanan. Kementerian Kelautan dan Perikanan telah berupaya meningkatkan ketersediaan prasarana pendukung pelabuhan perikanan, serta mendorong investasi dari pihak swasta baik pada kegiatan hulu, proses produksi maupun kegiatan hilir untuk menunjang percepatan industrialisasi di sektor perikanan tangkap. Kementerian Kelautan dan Perikanan telah menginformasikan pada tahun 2013 menetapkan 11 lokasi model percontohan industrialisasi perikanan tangkap, yaitu 5 lokasi pelabuhan komoditas tuna tongkol cakalang (TTC) dan 6 lokasi untuk komoditas non TTC (pelagis kecil dan udang).

Pembangunan dan pengembangan pelabuhan perikanan tersebut sebagai upaya untuk menciptakan pusat-pusat pertumbuhan ekonomi yang bertumpu pada komoditas kelautan dan perikanan. Selain itu untuk mewujudkan implementasi dari Peraturan Presiden No.26/2012 terkait cetak biru pengembangan sistem logistik nasional serta mewujudkan Program Peningkatan Kehidupan Nelayan (PKN) yang sebelumnya telah ditetapkan dan Kepres Nomor 10 tahun 2011.

PPN Pelabuhanratu merupakan Pelabuhan Perikanan Nusantara yang mampu melayani pendaratan kapal penangkap ikan berkapasitas sampai $100 \mathrm{GT}$, dan menjadi salah satu tempat pusat pelelangan ikan. Komoditas ikan yang menjadi andalan adalah ikan jenis tuna, tongkol, cakalang (TTC) dan layur. Komoditas TTC memegang peranan penting di PPN Pelabuhanratu dan menjadi komoditas ekspor andalan, khususnya ke Korea, Jepang, dan China.

Hasil dari komoditas TTC telah berkontribusi besar terhadap pengembangan industrialisasi di Pelabuhanratu, sehingga perlu dilakukan upaya untuk percepatan dan pengelolaannya secara maksimal. Hal tersebut turut pula didukung dengan Wilayah Pengelolaan Perikanan (WPP-RI) 573 yang terletak di Samudera Indonesia terutama di Pantai Selatan Jawa Barat masih berada pada level eksploitasi moderat (sumberdaya perikanan yang masih dapat ditingkatkan). Sehubungan dengan itu, Kabupaten Sukabumi telah mempunyai tujuh Pangkalan Pendaratan Ikan (PPI).

\subsection{Perumusan Masalah}

Apakah PPN Pelabuhanratu dapat dinaikkan kelasnya dari kelas PPN menjadi kelas PPS berdasarkan berdasarkan Peraturan Menteri Kelautan dan Perikanan nomor 16 tahun 2006. Dan melakukan kajian untuk pemilihan konsep dan karakteristik kapal penangkap ikan yang layak beroperasi pada perairan pelabuhan tersebut, penilaiannya berdasarkan survey lapangan, data, dan analisis SWOT.

\subsection{Tujuan}

Untuk mengetahui peluang pengembangan PPN Pelabuhanratu menjadi PPS Pelabuhanratu serta pemilihan konsep dan karakteristik kapal penangkap ikan yang layak beroperasi pada perairan pelabuhan tersebut sebagai dukungan untuk meningkatkan produksi perikanan tangkap

\subsection{Urgensi Penelitian}

Kegiatan penelitian yang dilakukan menghasilkan target luaran sebagai berikut:

a. Jika PPN Pelabuhanratu dapat naik kelas dari kelas PPN menjadi kelas PPS, maka dapat meningkatkan produksi perikanan tangkap di Provinsi Jawa Barat.

b. Pengayaan Bahan Ajar (Mata kuliah Perancangan Kapal, Kapal Perikanan, Manajemen Pelabuhan, dan Kapal Khusus).

\section{TINJAUAN PUSTAKA}

\subsection{Wilayah Indonesia}

Indonesia merupakan negara kepulauan terbesar di dunia memiliki 17.480 pulau, dengan garis pantai terpanjang ke empat di dunia yaitu $95.150 \mathrm{~km}$ setelah Kanada, USA dan Federasi Rusia. Berdasarkan konvensi PBB tahun 1982, tentang hukum laut, wilayah laut yang dapat dimanfaatkan seluas 5,8 juta $\mathrm{km}^{2}$ dengan rincian 3,1 juta $\mathrm{km}^{2}$ perairan teritorial dan 2,7 juta $\mathrm{km}^{2}$ Zona Ekonomi Ekslusif dan Indonesia memiliki garis pantai terpanjang keempat di dunia dengan panjang mencapai lebih dari $95.181 \mathrm{~km}$ [Lukito detiknews.com, 2009]. Perairan ZEE Indonesia yang sangat luas tersebut sudah pasti mempunyai kekayaan aneka ragam jenis ikan maupun migrasi ikan dapat dimanfaatkan untuk konsumsi 
kebutuhan dalam negeri maupun untuk ekspor guna menambah devisa negara.

\subsection{Moratorium Peraturan Menteri Kelautan dan Perikanan}

Peraturan Menteri Kelautan dan Perikanan nomor 2 tahun 2015 tentang larangan penggunaan alat penangkap ikan (API) pukat hela (trawl) dan pulat tarik (seine nets) di wilayah Pengelolaan Perikanan Negara Republik Indonesia. Akibat peraturan ini banyak kapal pengangkap ikan yang menggunakan alat penangkap ikan jenis tersebut tidak dapat beroperasi, mengakibatkan banyak para nelayan yang tidak melaut untuk mencari ikan. Selanjutnya Peraturan Menteri Kelautan dan Perikanan nomor 56 tahun 2014 tentang Pelarangan Berlayar Bagi Kapal Eks Asing. Dampak pemberlakuan Peraturan Menteri Kelautan dan Perikanan nomor 56 tahun 2014 tersebut, maka dari jumlah 1.320 kapal penangkap ikan eks asing tersebut tercatat sebagai milik dari 187 buah perusahaan dan perorangan dari Indonesia, terdapat 870 kapal penangkap ikan eks asing tidak dapat lolos kualifikasi dan dapat dikatagorikan sebagai illegal fishing, sehingga Indonesia memerlukan kapal penangkap ikan baru dimana alat penangkapikan bukan jenis jaring dan ramah lingkungan.

\subsection{Penelitian Terdahulu:}

a. Aep Saepurahman (2012), "Pengembangan Pelabuhan Perikanan Di Pelabuhan Ratu”, melakukan penelitian dan menyimpulkan terdapat peningkatan dari jumlah kunjungan kapal, jumlah nelayan, jumlah produksi dan nilai ikan, jumlah pasokan logistik yang terdiri dari BBM, minyak pelumas, es, air tawar, dan umpan, sehingga dari hasil pengolahan data tersebut dijadikan dasar untuk meningkatkan kelas dari PPN Pelabuhanratu menjadi PPS.

b. Daniel, John Haluan, dkk (2011), "Model Pengembangan Industri Perikanan Berbasis Pelabuhan Perikanan di Kota Makassar", penelitian dilakukan mulai Maret sampai dengan November 2009, mengambil data primer dari para responden yang terdiri dari logistik perikanan, manejemen perikanan, ekspotir perikanan, dari hasil penelitian berdasarkan analisis statistik seperti ChiSquare, Probabilias, RMSEA,CFI, IFI, AGFI, PGPI, menyimpulkan adanya peningkatan.

c. Baheramsyah (2012), "Kementerian Kelautan Dan Perikanan Soroti Perkembangan Perikanan”. Dalam pembangunan dan pengembangan pelabuhan perikanan, harus senantiasa melewati 3 tahap yaitu; tahap perencanaan (study, investigasi, detail design), kedua tahap pembangunan (construction), ketiga tahap operasional dan pelaksanaan dan pemeliharaan (operational and maintenance). Untuk mengurangi angka kemiskinan di sentra-sentra perikanan yang dimiliki Kementerian Kelautan dan Perikanan, sejak tahun 2011 telah melakukan Program Nasional Pemberdayaan Masyarakat (PNPM), yaitu PNPM Mandiri Kelautan, Program Usaha Mina Pedesaan (PUMP), dan Pemberdayaan Usaha Garam Rakyat (PUGR) dapat merealisasikan bantuan sebesar $\mathrm{Rp}$ 408,23 miliar kepada 5.312 kelompok.

d. Pramudya Edi, dkk, 2006, “Analisis Efisiensi Pelabuhan Perikanan dan Strategi Pengembangan Pelabuhan Cilacap”. Dalam rangka meningkatkan efisiensi kinerja untuk menentukan arah dan strategi pengembangannya. Dari 19 pelabuhan perikanan hanya 4 yang tidak efisien. Tingkat skala pengembangan (return to scala) dari Pelabuhan Perikanan Samudera (PPS), PPS Cilacap menunjukkan peningkatan efisiensi (25 - 27) \%. Variabel input yang tidak efisien adalah personil keamanan pelabuhan, penyaluran logistik yaitu es batu dan bahan bakar minyak, dan fasilitas pelabuhan. Setelah dilakukan konfirmasi dengan responden, maka strategi pengembangan untuk peningkatan efisisiensi adalah penyempurnaan sarana prasarana, peningkatan K3, pembinaan nelayan, pengawasan mutu, penciptaan iklim usaha yang kondusif.

e. Abbas Salim, 2005, Beberapa faktor yang perlu mendapat perhatian serta pertimbangan dalam pengembangan pelabuhan, 2005), yaitu:

1) Pertumbuhan/perkembangan ekonomi daerah pendukung (hinterland) dari pelabuhan yang bersangkutan.

2) Perkembangan industri yang terkait dengan pelabuhan.

3) Data arus muatan sekarang dan perkiraan yang akan datang.

4) Tipe dan ukuran kapal yang diperkirakan akan memasuki pelabuhan.

5) Jaringan jalan dan rel (prasarana dan sarana angkutan dari/ke wilayah hinterland).

6) Alur masuk/keluar menuju laut/pelabuhan.

7) Aspek nautis dan hidraulis.

8) Dampak keselamatan dan lingkungan hidup.

9) Analisis ekonomi dan keuangan. 


\subsection{Data dan informasi:}

Tabel 2. Karakteristik Kelas Pelabuhan Kepmen KKP no 16 Th. 2006, sebagai berikut:

\begin{tabular}{|c|c|c|c|c|c|}
\hline No & $\begin{array}{c}\text { Kriteria Pelabuhan } \\
\text { Perikanan }\end{array}$ & PPS & PPN & PPP & PPI \\
\hline 1 & $\begin{array}{l}\text { Daerah operasional kapal } \\
\text { ikan yang dilayani }\end{array}$ & $\begin{array}{l}\text { Wilayah laut } \\
\text { teritorial, Zona } \\
\text { Ekonomi Ekslusif } \\
\text { (ZEEI) dan perairan } \\
\text { internasional }\end{array}$ & $\begin{array}{l}\text { Perairan ZEEI dan } \\
\text { laut territorial }\end{array}$ & $\begin{array}{l}\text { Perairan } \\
\text { pedalaman, } \\
\text { perairan } \\
\text { kepulauan, laut } \\
\text { teritorial, wilayah } \\
\text { ZEEI } \\
\end{array}$ & $\begin{array}{l}\text { Perairan } \\
\text { pedalaman dan } \\
\text { perairan } \\
\text { kepulauan }\end{array}$ \\
\hline 2 & Fasilitas tambat/labuh kapal & $>60 \mathrm{GT}$ & 30-60 GT & $10-30 \mathrm{GT}$ & 3-10 GT \\
\hline 3 & $\begin{array}{l}\text { Panjang dermaga dan } \\
\text { Kedalaman kolam }\end{array}$ & $>300 \mathrm{~m}$ dan $>3 \mathrm{~m}$ & $\begin{array}{l}150-300 \mathrm{~m} \text { dan }>3 \\
\mathrm{~m}\end{array}$ & $\begin{array}{l}100-150 \mathrm{~m} \text { dan }>2 \\
\mathrm{~m}\end{array}$ & $\begin{array}{l}\text { 50-100 } \mathrm{m} \text { dan }>2 \\
\mathrm{~m}\end{array}$ \\
\hline 4 & $\begin{array}{l}\text { Kapasitas menampung } \\
\text { Kapal }\end{array}$ & $\begin{array}{l}6000 \mathrm{GT} \\
\text { (ekivalen dengan } \\
100 \text { buah kapal } \\
\text { berukuran } 60 \mathrm{GT} \text { ) }\end{array}$ & $\begin{array}{l}2250 \text { GT } \\
\text { (ekivalen dengan } \\
75 \text { buah kapal } \\
\text { berukuran } 30 \mathrm{GT} \text { ) }\end{array}$ & $\begin{array}{l}\text { >300 GT } \\
\text { (ekivalen dengan } \\
30 \text { buah kapal } \\
\text { berukuran } 10 \mathrm{GT} \text { ) }\end{array}$ & $\begin{array}{l}\text { >60 GT } \\
\text { (ekivalen dengan } \\
20 \text { buah kapal } \\
\text { berukuran } 3 \text { GT) }\end{array}$ \\
\hline 5 & $\begin{array}{l}\text { Volume ikan yang } \\
\text { didaratkan }\end{array}$ & Rata-rata 60 ton/hari & $\begin{array}{l}\text { Rata-rata } 30 \\
\text { ton/hari }\end{array}$ & - & - \\
\hline 6 & Ekspor ikan & Ya & $\mathrm{Ya}$ & Tidak & Tidak \\
\hline 7 & Luas lahan & $>30 \mathrm{Ha}$ & $15-30 \mathrm{Ha}$ & 5-15 Нa & $2-5 \mathrm{Ha}$ \\
\hline 8 & $\begin{array}{l}\text { Fasilitas pembinaan mutu } \\
\text { hasil perikanan }\end{array}$ & Ada & Ada/Tidak & Tidak & Tidak \\
\hline 9 & $\begin{array}{l}\text { Tata ruang (zonasi) } \\
\text { pengolahan/pengembangan } \\
\text { industri perikanan }\end{array}$ & Ada & Ada & Ada & Tidak \\
\hline
\end{tabular}

\section{BAB 3. METODE PENELITIAN}

\subsection{Rancangan Penelitian}

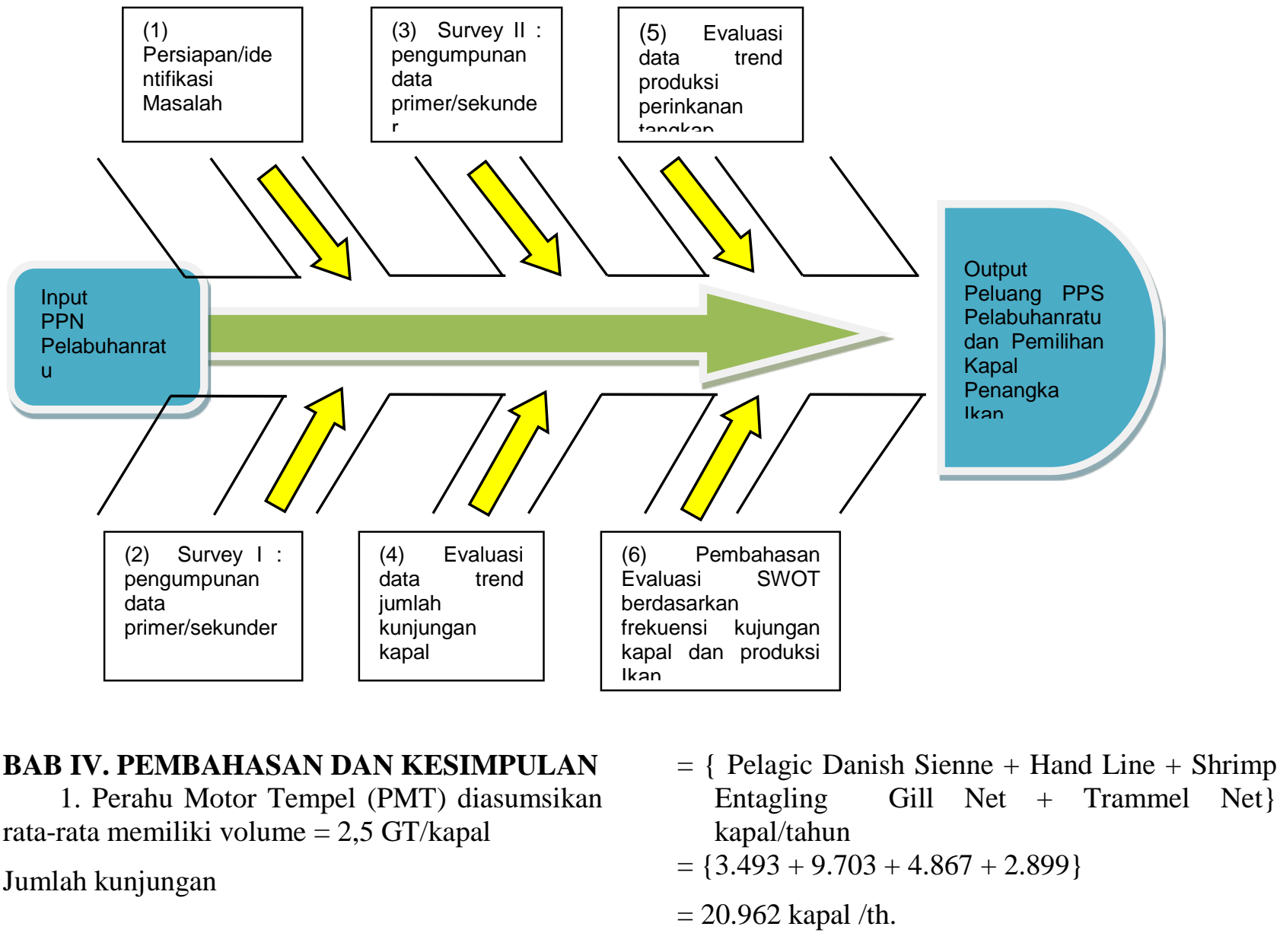


Jumlah volume kapal

$=\{$ Jumlah Armada Kapal x Rata-rata GT $\}$

$=\{20.962 \mathrm{kpl} /$ thn $\times 2,5 \mathrm{GT} / \mathrm{kpl}=52.405 \mathrm{GT} / \mathrm{thn}$

$=4.367 \mathrm{GT} / \mathrm{bln}=143,575 \mathrm{GT} / \mathrm{hari}$

2. Kapal Motor 5-10 GT diasumsikan rata-rata memiliki volume $=7,5 \mathrm{GT} / \mathrm{kapal}$

Jumlah kunjungan

$=\{$ Raft Lift Net + Pelagic Danish Sienne + Shrimp Entagling Gill Net + Gill + Purse Sienne + Troll line $\}$ kapal/tahun

$=\{2.074+65+94+6+38+1.271\} \mathrm{kapal} / \mathrm{th}$.

$=3.548 \mathrm{kapal} / \mathrm{tahun}$

Jumlah volume kapal

$=\{$ Jumlah Armada Kapal $\mathrm{x}$ Rata-rata GT $\}$

$=\{3.548 \mathrm{kpl} /$ thn $\times 7,5 \mathrm{GT} / \mathrm{kpl}\}=26.610 \mathrm{GT} / \mathrm{thn}$

$=2.217,50 \mathrm{GT} / \mathrm{bln}=72,904 \mathrm{GT} / \mathrm{hari}$

3. Kapal Motor $10-20$ GT diasumsikan rata-rata memiliki volume $=15 \mathrm{GT} / \mathrm{kapal}$

Jumlah kunjungan

$=\{$ Shrimp Entagling Gill Net + Tunalong Line $\}$

kapal/tahun

$=\{39+8\} \mathrm{kapal} / \mathrm{th}$.

$=47 \mathrm{kapal} /$ tahun

Jumlah volume kapal

$=\{$ Jumlah Armada Kapal x Rata-rata GT $\}$

$=\{47 \mathrm{kpl} /$ thn $\times 15 \mathrm{GT} / \mathrm{kpl}\}=705 \mathrm{GT} / \mathrm{thn}$

$=50,75 \mathrm{GT} / \mathrm{bln}=2 \mathrm{GT} / \mathrm{hari}$

4. Kapal Motor 20 - 30 GT diasumsikan rata-rata memiliki volume $=25 \mathrm{GT} / \mathrm{kapal}$

Jumlah kunjungan

$=\{$ Shrimp Entagling Gill Net + Gil Net \& Bottom Line + Tunalong Line $\}$ kapal/tahun

$=\{6+1+191\} \mathrm{kapal} / \mathrm{th}$.

$=198 \mathrm{kapal} / \mathrm{tahun}$

Total volume kapal

$=\{$ Jumlah Armada Kapal x Rata-rata GT $\}$

$=\{198 \mathrm{kpl} /$ thn $\times 25 \mathrm{GT} / \mathrm{kpl}\}=4.950 \mathrm{GT} / \mathrm{thn}$

$=412,5 \mathrm{GT} / \mathrm{bln}=13,561 \mathrm{GT} / \mathrm{hari}$

5. Kapal Motor 30 - 50 GT diasumsikan rata-rata memiliki volume $=40 \mathrm{GR} / \mathrm{kapal}$

Jumlah kunjungan

$=\{$ Tuna Longline $\} \mathrm{kapal} / \mathrm{tahun}$

$=\{50\} \mathrm{kapal} / \mathrm{th} .=50 \mathrm{kapal} / \mathrm{tahun}$

Total volume kapal
$=\{$ Jumlah Armada Kapal x Rata-rata GT $\}$

$=\{50 \mathrm{kpl} / \mathrm{thn} \times 40 \mathrm{GT} / \mathrm{kpl}\}=2.000 \mathrm{GT} / \mathrm{thn}$

$=166,667 \mathrm{GT} / \mathrm{bln}=5,479 \mathrm{GT} / \mathrm{hari}$

6. Kapal Motor 50 - 100 GT diasumsikan rata-rata memiliki volume $=75 \mathrm{GT} / \mathrm{kapal}$

Jumlah kunjungan

$=\{$ Tuna Longline $\}$ kapal $/$ tahun

$=\{61\} \mathrm{kapal} / \mathrm{th}$.

$=61 \mathrm{kapal} / \mathrm{tahun}$

Jumlah volume kapal

$=\{$ Jumlah Armada Kapal $\mathrm{x}$ Rata-rata GT $\}$

$=\{61 \mathrm{kpl} /$ thn $\times 75 \mathrm{GT} / \mathrm{kpl}\}=4.575 \mathrm{GT} / \mathrm{thn}$

$=381,25 \mathrm{GT} / \mathrm{bln}=12,535 \mathrm{GT} / \mathrm{hari}$

7. Kapal Motor 100 - 200 GT diasumsikan ratarata memiliki volume $=150 \mathrm{GT} / \mathrm{kapal}$

Jumlah kunjungan

$=\{$ Tuna Longline + Purse Sienne $\}$ kapal/tahun

$=\{45+1\} \mathrm{kapal} / \mathrm{th}$.

$=46 \mathrm{kapal} / \mathrm{tahun}$

Total volume kapal

$=\{$ Jumlah Armada Kapal x Rata-rata GT $\}$

$=\{46 \mathrm{kpl} /$ thn $\times 150 \mathrm{GT} / \mathrm{kpl}\}=6.900 \mathrm{GT} / \mathrm{thn}$

$=575 \mathrm{GT} / \mathrm{bln}=18,904 \mathrm{GT} / \mathrm{hari}$

Tabel 4.1 : Frekuensi Kunjungan Dan Volume Kapal Penangkap Ikan (0 - 50 GT)

\begin{tabular}{|c|c|r|r|r|r|}
\hline No & $\begin{array}{c}\text { Jenis } \\
\text { Kapal } \\
\text { Penangkap } \\
\text { IKan }\end{array}$ & $\begin{array}{c}\text { Frekuensi } \\
\text { Kapal } \\
\text { /Tahun }\end{array}$ & $\begin{array}{c}\text { Volume } \\
\text { GT } \\
\text { /Tahun }\end{array}$ & $\begin{array}{c}\text { Volume } \\
\text { GT } \\
\text { /Bulan }\end{array}$ & $\begin{array}{c}\text { Volume } \\
\text { GT } \\
\text { /Hari }\end{array}$ \\
\hline 1 & $\begin{array}{c}\text { Motor } \\
\text { Tempel 2,5 } \\
\text { GT }\end{array}$ & 20.962 & 52.405 & 4.367 & 143,575 \\
\hline 2 & $\begin{array}{c}\text { Kapal } \\
\text { Motor 5 } \\
\text { 10 GT }\end{array}$ & 3.548 & 26.610 & $2.217,50$ & 72,904 \\
\hline 3 & $\begin{array}{c}\text { Motor } \\
\text { Tempel 10 } \\
-20 \text { GT }\end{array}$ & 47 & 705 & 50,75 & 2 \\
\hline 4 & $\begin{array}{c}\text { Motor } \\
\text { Tempel 20 } \\
-30 \text { GT } \\
\text { Motor } \\
\text { Tempel 30 } \\
-50 \text { GT }\end{array}$ & 198 & 4.950 & 412,5 & 13,561 \\
\hline 5 & 50 & 2.000 & 166,667 & 5,479 \\
\hline \\
Total
\end{tabular}


Tabel 4.2 : Frekuensi Kunjungan Dan Volume Kapal Penangkap Ikan (50 - 200) GT

\begin{tabular}{|l|c|r|r|r|r|}
\hline No & $\begin{array}{c}\text { Jenis } \\
\text { Kapal } \\
\text { Penangkap } \\
\text { IKan }\end{array}$ & $\begin{array}{c}\text { Frekuensi } \\
\text { Kapal } \\
\text { /Tahun }\end{array}$ & $\begin{array}{c}\text { Volume } \\
\text { GT } \\
\text { /Tahun }\end{array}$ & $\begin{array}{c}\text { Volume } \\
\text { GT } \\
\text { /Bulan }\end{array}$ & $\begin{array}{c}\text { Volume } \\
\text { GT/Hari }\end{array}$ \\
\hline 1 & $\begin{array}{c}\text { Kapal } \\
\text { Motor 50 } \\
\text { 100 GT }\end{array}$ & 61 & 4.575 & 381,25 & 12,534 \\
\hline 2 & $\begin{array}{c}\text { Kapal } \\
\text { Motor 100 } \\
-200 \text { GT }\end{array}$ & 46 & 6.900 & 575 & 18,904 \\
\hline \multicolumn{7}{|c|}{ Total } & $\mathbf{1 0 7}$ & $\mathbf{1 1 . 4 7 5}$ & $\mathbf{9 5 6 , 2 5}$ & $\mathbf{3 1 , 4 3 8}$ \\
\hline
\end{tabular}

Total Frekuensi Kapal Penankap Ikan

$=$ Frek. Kpl $(0-50)$ GT + Fre. Kpl.(50 - 200) GT

Total Frekuensi Kapal Penankap Ikan

$=24.805+107$

$=24.912 \mathrm{kapal} / \mathrm{hari}$

Total Volume Kapal Penangkap Ikan

$=$ Frek. Kpl $(0-50)$ GT + Fre. Kpl.(50 - 200) GT

Total Volume Kapal Penangkap Ikan

$=237,519+31,438$

$=268,957$ GT/hari

Tabel 4.3. : Produksi Perikanan Tangkap 3 Tahun Terakhir

\begin{tabular}{|c|c|c|c|c|}
\hline \\
\hline no & Bulan & 2013 & 2014 & 2015 \\
\hline 1 & Januari & 637.257 & 941.617 & 1.048 .216 \\
\hline 2 & Pebruari & 439.013 & 619.133 & 514.008 \\
\hline 3 & Maret & 329.656 & 582.889 & 436.176 \\
\hline 4 & April & 469.653 & 701.496 & 572.952 \\
\hline 5 & Mei & 853.987 & 1.074 .079 & 914.047 \\
\hline 6 & Juni & 945.444 & 1.240 .977 & 1.168 .243 \\
\hline 7 & Juli & 696.582 & 1.027 .744 & 1.312 .412 \\
\hline 8 & Agustus & 395.329 & 410.135 & 621.668 \\
\hline 9 & September & 600.024 & 717.588 & 703.195 \\
\hline 10 & Oktober & 976.085 & 985.647 & 785.104 \\
\hline 11 & Nopember & 753.449 & 873.037 & 551.916 \\
\hline 12 & Desember & 832.594 & 1.182 .681 & 494.383 \\
\hline & Jumlah & 7.929 .073 & 10.357 .023 & 9.122 .320 \\
\hline
\end{tabular}

Sumber : Statistik Perikanan Tangkap Tahun 2015, halaman 38 PPN Pelabuhanratu

Jumlah Rata-rata Produksi Perikanan Tangkap = $\left\{\frac{\text { Prod.2013+Prod.2014+Prod.2015 }}{3}\right\} \mathrm{kg} / \mathrm{th}$

Jumlah Rata-rata Produksi Perikanan Tangkap = $\left\{\frac{7.929 .073+10.357 .023+9.122 .320}{3}\right\} \mathrm{kg} / \mathrm{th}$
Jumlah Rata-rata Produksi Perikanan Tangkap = $\left\{\frac{27.408 .416}{3}\right\}=9.136 .138,667 \mathrm{~kg} / \mathrm{th}$

Jumlah Rata-rata Produksi Perikanan Tangkap = $250.030,516 \mathrm{~kg} / \mathrm{hari}=25,030$ ton/hari

\section{Hasil Analisis SWOT Kenaikan Kelas \\ Pelabuhan: \\ Strategi S-O}

- Perlu membantu kelompok nelayan Pelabuhanratu agar mempunyai armada kapal ikan yang layak beroperasi pada perairan Samudera (ZEE) yang memiliki rumpon ikan tuna, tongkol, cakalang, dan layur dengan alat tangkap ramah lingkungan

- Perlu menambah jumlah armada kapal penangkap ikan berukuran besar untuk menaikkan jumlah produksi perikanan tangkap, sebagai dukungan untuk proses kenaikan kelas pelabuhan perikanan.

\section{Strategi S-W}

- Perbaikan kelas PPN Pelabuhanratu menjadi PPS akan mengembangkan potensi ekonomi daerah seperti pariwisata, industri perikanan, peluang ekspor, peluang penyerapan tenaga kerja.

- Kelompok nelayan Pelabuhanratu perlu bantuan teknologi dan armada kapal penangkap ikan berkapasitas besar > 60 GT dengan menggunakan alat pancing (handline), agar dapat beroperasi lebih dari 50 mil laut yang sangat potensi rumpon ikan dan migrasi ikan. dimana selama ini potensi perikanan tersebut diambil oleh kelompok nelayan dari Kalibaru Jakarta.

\section{Strategi S-T}

- Rencana pengembangan pelabuhan melibatkan Pemerintah Derah dan Pemerintah Pusat dalam hal pembebasan lahan untuk pengembangan pelabuhan

- Rencana pengembangan kapal penangkap ikan sebaiknya berukuran besar agar layak berlayar di luar 50 mil laut dari garis pantai dimana banyak potensi rumpon ikan tuna, tongkol, cakalang, dan layur dengan kecepatan 12,5 knots.

\section{Strategi W-T}

- Melakukan sosialisasi kepada para nelayan Pelabuhanratu agar beralih menggunakan alat tangkap jenis pancing, karena penggunan alat tangkap jenis jaring dapat merusak lingkungan. 
Konsep rancangan kapal penangkap ikan kelompok nelayan Pelabuhanratu yang sesuai dengan karateristik perairan samudera adalah:

\begin{tabular}{|c|c|c|}
\hline No. & Pokok bahasan & Pertimbangan rancangan kapal \\
\hline 1. & $\begin{array}{l}\text { Volume kapal = sama atau lebih besar } \\
\text { dari } 60 \mathrm{GT}\end{array}$ & $\begin{array}{l}\text { Volume kapal penangkap ikan }>60 \mathrm{GT} \text { atau lebih agar dapat beroperasi } \\
\text { pada perairan samudera karena potensi rumpon ikan atau migrasi ikan } \\
\text { terdapat pada zona perairan tersebut }\end{array}$ \\
\hline 2. & $\begin{array}{l}\text { Ukuran utama untuk kapal penangkap } \\
\text { ikan } 60 \mathrm{GT} \text { adalah panjang }=35 \mathrm{~m} \text {, } \\
\text { lebar }=3,8 \mathrm{~m} \text {, tinggi }=2,0 \mathrm{~m} \text {, perkiraan } \\
\mathrm{Cb}=0,65 \text {. }\end{array}$ & $\begin{array}{l}\text { Ukuran utama dimaksud untuk volume kapal } 60 \text { GT, besaran ukuran utama } \\
\text { tersebut perlu koreksi terhadap stabilitas, trim, dan olah gerak kapal. } \\
\text { Harga perbandingan L/B yang besar akan berpengaruh kepada olah gerak } \\
\text { kapal, kebaikannya penysunan ruangan memanjang kapal akan lebih } \\
\text { mudah. Sebaliknya perbandingan L/B kecil akan berpengaruh kepada } \\
\text { bertambah baiknya stabilitas kapal tetapi tahanan kapal menjadi lebih besar. } \\
\text { Perbandingan L/H besar akan berpengaruh berkurangnya kekuatan } \\
\text { memanjang, sebaliknya jika L/H kecil akan menambah baik kekuatan } \\
\text { memanjang kapal. } \\
\text { Perbandingan H/T besar akan berpengaruh kepada bertambahnya cadangan } \\
\text { apung (reserve displasement), sebaliknya harga H/T kecil akan mengurangi } \\
\text { cadangan apung (H-T) atau lambung timbul (free board). }\end{array}$ \\
\hline 3. & Kecepatan kapal minimal 12,5 knots & $\begin{array}{l}\text { Kecepatan minimal tersebut agar waktu pelayaran dapat lebih cepat, } \\
\text { khususnya saat menuju rumpon ikan di perairan samudera dan merapat ke } \\
\text { dermaga. }\end{array}$ \\
\hline 4. & $\begin{array}{l}\text { Tempat palka ikan atau fish hold atau } \\
\text { cold storage berada di tengah lambung } \\
\text { kapal dan berjumlah minimal } 6 \text { buah. }\end{array}$ & $\begin{array}{l}\text { Fish hold atau cold storage berada di tengah kapal. Keadaan ini dilakukan } \\
\text { agar naik dan turunnya sarat air dapat merata (even keel) jika beban muatan } \\
\text { kapal bertambah. } \\
\text { Fish hold berjumlah minimal } 6 \text { buah agar posisi ikan tangkapan yang } \\
\text { berada di dalam fish hold tidak mudah bergerak atau goncang akibat } \\
\text { pengaruh maju dan mundurnya kapal, dan mempermudah mengatur muatan } \\
\text { ikan agar mempermudah mengatur posisi trim kapal. }\end{array}$ \\
\hline 5. & $\begin{array}{l}\text { Jumlah awak kapal (kelompok nelayan) } \\
10-15 \text { orang }\end{array}$ & $\begin{array}{l}\text { Jumlah tersebut harus disesuaikan dengan layout rencana umum kapal dan } \\
\text { volume kapal. }\end{array}$ \\
\hline 6. & $\begin{array}{l}\text { Lambung kapal perlu dilengkapi sirip } \\
\text { (bilge keel) }\end{array}$ & $\begin{array}{l}\text { Keberadaan bilge keel untuk memperlambat periode oleng kapal, jika } \\
\text { periode oleng lambat maka kondisi ikan di dalam fish hold tidak mengalami } \\
\text { goncangan oleng ke kanan dan oleng ke kiri, sehingga kualitas ikan tidak } \\
\text { mudah rusak. Apalagi jika pendingin ikan menggunakan balok es. }\end{array}$ \\
\hline 7. & $\begin{array}{l}\text { Bahan kapal terbuat dari kayu, baja, } \\
\text { aluminium, atau fiberglass }\end{array}$ & $\begin{array}{l}\text { Pemilihan bahan kapal tergantung dari kebiasaan nelayan dalam merawat } \\
\text { lambung kapal, pertimbangan harga, dan pertimbangan life time serta } \\
\text { kekuatannya. }\end{array}$ \\
\hline 8. & Bentuk Rencana Umum & $\begin{array}{l}\text { Disesuaikan dengan budaya nelayan setempat, khususnya bentuk linggi } \\
\text { haluan. } \\
\text { Bangunan atas (super struture) atau rumah geladak (deck house) berada di } \\
\text { bagian buritan kapal, gudang berada di haluan kapal, mesin utama berada di } \\
\text { dalam ruang mesin (in board). }\end{array}$ \\
\hline
\end{tabular}

Kesimpulan pengembangan Pelabuhanratu dari PPN menjadi PPS dan konsep kapal pengangkap ikan yang sesuai sengan perairan Pelabuhanratu:

a. Persyaratan menjadi Pelabuhan Perikanan Samudera adalah daerah operasi kapal penangkap ikan berada pada wilayah laut teritorial ZEE dan perairan internasional, fasilitas tambat $>60 \mathrm{GT}$, panjang dermaga dan kedalaman kolam $>300 \mathrm{~m}$ dan $>3 \mathrm{~m}$, jumlah produksi perikanan tangkap 60 ton per hari, frekuensi keluar kapal penangkap ikan ekivalen dengan 100 buah kapal berkapasitas 60 GT per hari, adanya fasilitas pembinaan mutu hasil perikanan, luas lahan pelabuhan perikanan > 30 hektar dan terdapat zonasi pengolahan/pengembangan industri perikanan.

b. Hasil penelitian terdapat beberapa faktor yang belum sesuai dengan peraturan KKP yaitu total produksi perikanan 25,030 ton/hari, total gross tonnage kunjungan kapal 268,957 GT per hari, luas area pelabuhan perikanan < 30 hektar, zonasi industri pengolahan perikanan belum lengkap. Sehingga PPN Pelabuhanratu belum dapat dinaikkan karekteristik kelasnya menjadi Pelabuhan Perikanan Samudera.

c. Kelompok nelayan Pelabuhanratu pada umumnya hanya mempunyai armada kapal penangkap ikan berkapasitas 30 GT dengan alat tangkap pancing (handline) dan jaring, dimana satu kapal pengangkap ikan rata-rata mempunyai 10 orang nelayan.

d. Perairan Pelabuhanratu sangat berpotensi memiliki rumpon ikan tuna, tongkol, cakalang, dan layur khususnya pada daerah perairan samudera (ZEE) yaitu pada daerah operasi lebih 50 mil laut dari garis pantai. Tetapi potensi rumpon ikan tersebut sebagian besar dimanfaatkan oleh kelompok nelayan dari luar Pelabuhanratu yaitu kelompok 
nelayan Kalibaru Jakarta yang memiliki armada kapal penangkap ikan > 50 GT.

e. Perlu membantu kelompok nelayan Pelabuhanratu untuk memiliki armada kapal penangkap ikan > $60 \mathrm{GT}$, sebagai dukungan untuk meningkatkan produksi perikanan tangkap.

f. Konsep rancangan kapal pengangkap ikan yang layak beroperasi pada perairan PPN Pelabuhanratu adalah :

- Kapal penangkap ikan dengan kapasitas $\geq 60$ GT, dengan ukuran utama;

- Panjang $=35 \mathrm{~m}$,

- Lebar = =3,8,

- Tnggi $=2,0 \mathrm{~m}$

- Alat tangkap pancing

- Kecepatan kapal minimal 12,5 knots

- Palka Ikan atau Fish Hold atau Cold Storage minimal 6 buah dan posisinya berada di bagian tengah lambung kapal

- Jumlah awak kapal 10 sampai dengan 15 orang.

- Lambung kapal pengankap ikan dilengkapi sirip (bilge keel).

f. Perlu penelitian lanjutan

\section{Dafrat Pustaka:}

Baheramsyah (2012), Kementrian Kelautan Dan Perikanan Soroti Perkembangan Perikanan, www.infopublik.kominfo.go.id

Daniel dkk (2011), Model Pengembangan Industri Perikanan Berbasis Pelabuhan Perikanan di Makassar Sulawesi Selatan, Jurnal Penelitian UMI Makassar.

Helmi Yususf dkk (2005), Dampak Pengembangan Pelabuhan Perikanan Terhadap Penyerapan Tenaga Kerja Dan Pendapatan Masyarakat, www.journal.ipb.ac.id

Keputusan Menteri Perhubungan nomor: KM 53 Tahun 2002, Tentang Pelabuhan Nasional.

Kementerian Kelautan dan Perikanan, Pusat Informasi Pelabuhan Perikanan (PPIP), April 2015

Kementerian Kelautan dan Perikanan (2009), Profil Pelabuhan PPN Pelabuhan Ratu, www.kkp.go.id

Kementerian Kelautan dan Perikanan (2012), Profil Pelabuhan PPN Nizam Zachman Jakarta, www.kkp.go.id

Peraturan Menteri Kelautan Dan Perikanan nomor: Per.16/Men/2006, Tentang Pelabuhan Perikanan
Peraturan Menteri Kelautan dan Perikanan nomor 2 tahun 2015, tentang Larangan Penggunaan Alat Penangkap Ikan (API) Pukat Hela (Trawl) dan Pulat Tarik (Seine Nets) di Wilayah Pengelolaan Perikanan Negara Republik Indonesia.

Peraturan Menteri Kelautan dan Perikanan nomor 56 tahun 2014, tentang Pelarangan Berlayar Bagi Kapal Eks Asing

Pramudya Edy dkk (2006), Analisis Efisiensi Pelabuhan Perikanan Dan Strategi Pengembangannya (Pelabuhan Cilacap), Undip Semarang.

Rizald Max Rompas (2009), Garis Pantai RI Terpanjang Keempat Di Dunia, $\quad$ www.antaranews.com dan www.goblue.or.id

Salim H.A. Abbas (2005), Manajemen Pelayaran Niaga Dan Pelabuhan, Cetakan Kedua, Dunia Pustaka, Jakarta

UPT Ditjen Perikanan Tangkap (2012), Daftar Pelabuhan Perikanan Di Indonesia, www.kkp.go.id 